\title{
S5ynthesis
}

International Scientific Conference of IT and Business-Related Research

\section{UPOTREBA RODNO RAVNOPRAVNIH NAZIVA ZANIMANJA U ENGLESKOM JEZIKU STRUKE U SRBIJI}

\author{
THE USE OF GENDER SENSITIVE PROFESSIONAL TITLES \\ IN ESP (ENGLISH FOR SPECIFIC PURPOSES) IN SERBIA
}

\author{
Ivana Vranić, Mirjana Dišević, Dragica Mirković \\ Beogradska poslovna škola - Visoka škola strukovnih studija, Beograd, Srbija
}

\begin{abstract}
Apstrakt:
Ovaj rad ima za cilj da ispita upotrebu rodno ravnopravnih, odnosno neutralnih imenica koje označavaju nazive profesija/zanimanja žena među korisnicima/korisnicama poslovnog engleskog jezika kao L2 u Srbiji. Analiza je zasnovana na kritičkoj sociolingvistici, budući da ispituje upotrebu jezika, ali i stavove ispitanika/ispitanica prema jeziku i društvu. Sprovedeno istraživanje obuhvatilo je 56 muškaraca i žena korisnika poslovnog engleskog jezika koji će izneti lične stavove u vezi sa nazivima zanimanja u muškom i ženskom rodu, kod onih imenica gde je moguća rodna diferencijacija. Istraživanje je kvalitativnog tipa i rađeno je u periodu februar - mart 2015. godine. Na taj način, dobijeni rezultati će pokazati da li jezička praksa u poslovnom kontekstu utiče na generisanje kulturnih modela i kreira društvenu nejednakost pri raspodeli društvene moći.
\end{abstract}

\section{Ključne reči:}

poslovni engleski jezik, rodno osetljiv jezik, nazivi zanimanja, jezička ideologija.

\section{UVOD}

Savremeni trendovi globalizacije učinili su da engleski jezik postane lingua franca te je njegovo poznavanje, na solidnom nivou, postalo neizostavna veština koju svaka radno sposobna osoba mora da poseduje. Ukoliko sam jezik definišemo kao sistem znakova pomoću kog komuniciramo sa ostalim ljudima, odnosno članovima naše govorne zajednice, njegova analiza bi nam razotkrila o kakvoj se kulturnoj sredini radi, kakve ideologije vladaju, kakvi su stavovi, verovanja govornika i govornica određene govorne zajednice. Na taj način jezik, kao neodvojivi deo društvene prakse, odražava i rodnu ideologiju čije istraživanje nudi sliku o identitetu pojedinaca, hijerarhiji društvenog uticaja i javno vidljive ili implicitne društvene moći (Filipović, 2009).

Iako se tendencijama u savremenom društvenom sistemu insistira na ravnopravnosti polova, ipak, praksa koja se značajno odražava u jeziku, potvrđuje postojanje rodne neravnopravnosti i dominaciju muškaraca.

Ovaj rad ima za cilj da ispita stavove govornika/govornica poslovnog engleskog jezika u Srbiji prema upotrebi ženskog gramatičkog roda imenica koje se odnose na zanimanja ili titule žena. Referentna tačka ovog istraživanja jeste postojanje koncepta partrijahalnog kulturnog modela u Srbiji čija je posledica upravo nedovoljna upotreba rodno neutralnih naziva zani-

\section{Abstract:}

The main aim of this paper is to analyze the usage of gender equal nouns, also defined as gender neutral nouns, which designate professional titles/ occupations of women among users of business English as a second language in Serbia. The analysis is based on critical sociolinguistics, since it examines not only the use of language, but also the attitudes of examinees towards the language and the society. Research conducted included 56 men and women who use business English in professional environment and who have expressed personal opinions about the masculine and feminine forms of professional titles in relation to the nouns with differentiated gender. The method used was qualitative and the data were collected during the period February - March 2015. Hence, the data obtained will demonstrate whether generating of cultural models is affected by the language practice within business context, thus creating social inequality within the distribution of social power.

\section{Key words:}

Business English, gender-sensitive language, professional titles, language ideology.

manja, a što pokazuje nejednaku podelu društvene moći. Ovo je naročito vidljivo pri upotrebi muškog gramatičkog roda za zanimanja i titule žena u srpskom jeziku, pa se postavlja pitanje da li i pri upotrebi stranog jezika u kontekstu poslovne komunikacije, ESP govornici/govornice ipak koriste rodno neutralne, odnosno ravnopravne nazive. $\mathrm{S}$ tim u vezi, pretpostavka ovog empirijskog istraživanja, zasnovana na korpusu posebno kreirane ankete, počiva na činjenici da ispitanici/ispitanice rodnu ideologiju maternjeg jezika (a samim tim i jezički kod) preslikavaju i na upotrebu poslovnog engleskog jezika.

U prvom delu rada biće predstavljena perspektiva analize, odnosno teorijski okvir, dok će u drugom delu rada biti opisana kvalitativna analiza.

Implementacija rodno osetljivog engleskog jezika u poslovnom kontekstu predstavlja jedan od važnih činilaca koji bi doprineli usvajanju ravnopravne rodne ideologije u društvu i razvijanju svesti o vidljivosti ženskog identiteta.

\section{TEORIJSKI OKVIR}

Potreba za ESP, kao globalno dominantnim instrumentom sporazumevanja, rezultirala je velikim interesovanjem lingvista za ovu oblast. Stoga danas postoje brojne teorije jezika o tome na koji način treba izučavati engleski jezik za posebne namene. 
Frendo (2007: 1-7) poslovni engleski jezik opisuje kao komunikaciju sa drugim ljudima u posebnom kontekstu, gde je poslovni engleski jezik u tesnoj vezi sa opštim engleskim jezikom, opštim poslovnim engleskim jezikom i engleskim jezikom za posebne namene. Smatra se da ono što razlikuje opšti engleski jezik od poslovnog jezika, tj. ESP, jeste najvećim delom posebna leksika, ali i gramatičke strukture i registar. Prema Harmeru (2006: 14) sam kontekst upotrebe ESP zahteva različite žanrove pisanja, govorenja, ali i veštine interakcije.

Iako engleski jezik nema produktivne obrasce, odnosno nastavke za građenje roda imenica, ipak u engleskom jeziku distinkcija između muškog i ženskog roda može biti sačinjena pomoću leksičkih parova (man-woman), ali i pomoću eksplicitnih formalnih markera (Biber et al., 1999: 312): rodno specifičnih modifikacija kao na primer male secretary ili female lawyer; slaganjem rodno specifičnih elemenata kao u primeru chairman/chairwoman; upotreba rodno posebnih derivativnih nastavaka(-ess) governess. Međutim, rod u engleskom jeziku je najpre semantička kategorija sa različitim implikacijama, a jedna od njih jeste tendencija da pojedine imenice trpe semantička odstupanja kao što su herione, aviatrix, usherette (Fuertes Olivera et al., 2003: 73). U tom pogledu, srpski jezik je mnogo produktivniji u konstruisanju rodno diferenciranih imenica koje označavaju nazive profesija/zanimanja/titula, mada i dalje vlada mišljenje da takvi izrazi rogobatno zvuče i kao takvi da su neprihvatljivi. Međutim, „rogobatni” oblici imenica u ženskom rodu „nisu lingvističke kategorije i ne mogu se uzimati kao valjan argument" (Čaušević \& Zlotrg, 2011: 12).

Dominacija muškog roda u jezičkoj praksi vidljiva je u upotrebi parova reči u muškom i ženskom rodu. Naime, može se primetiti da upotreba pojedinih imenica u ženskom rodu najčešće se interpretira negativno ili pak se ženski rod upotrebljava u „konotaciji negativne stručnosti” (Gvozdanović, 2010: 228). Primer ovoga, dala je Robin Lejkof (2004: 60):

- He is a professional.

- She is a professional.

Kako ona zapaža, većina govornika engleskog jezika (ali i srpskog) prvu rečenicu će shvatiti da je on veliki stručnjak u svom poslu, dok će drugu rečenicu shvatiti da se radi o ženi lakog morala.

Sve do 1983. godine, na engleskom govornom području, postojali su nazivi white-collar workers i blue-collar workers koji su implicirali da se radi o radno sposobnim muškarcima. Međutim, kako je broj zaposlenih žena rastao, javila se potreba da se zvanično uvede termin white-blouse workers, koji će upućivati na to da su u fabrici ili preduzeću zaposlene i žene (Gamarnikow, 1983: 169). Međutim, kako Gamarnikov (1983) navodi, uloga žena je i dalje bila podređena porodici i porodičnim obavezama; prekid karijere zarad rađanja i podizanja dece, te je ženama bila uskraćena mogućnost da napreduju u karijeri i da zarađuju više od svojih kolega.

Treba uzeti u obzir činjenicu da je profesija i zanimanje osobe relevantno obeležje identiteta, pa je s te strane upotreba ženskog gramatičkog roda za zanimanja i titule žena vrlo važan deo afirmacije žena i stvaranja ,ženskih uzora u javnoj sferi društvenog života" (Filipović, 2009: 137).

U kontekstima upotrebe poslovnog engleskog jezika među govornicima u Srbiji, može se primetiti da žene i muškarci primenjuju različite obrasce verbalnog i neverbalnog ponašanja, koje su verovatno preuzeli iz svog maternjeg jezika. Međutim, učenje i kasnije upotreba drugog jezika „zahteva i usvajanje novih konceptualnih sistema i konstrukciju nove mreže vokabulara- drugi mentalni leksikon" (Thornbury, 2002: 18). To se može tumačiti i da je neophodno širenje sopstvene mreže asocijacija o rodu i adaptirati konceptualne strukture preuzete iz maternjeg jezika potrebama, u najmanju ruku, rodno neutralne komunikacije između muškaraca i žena na poslovnom engleskom jeziku.

Komunikacija na radnom mestu je prevashodno određena poslovnom situacijom, vremenom, kulturom govornika, ali pre svega njihovom jezičkom ideologijom. Kameron (2003: 447-448) definiše jezičku ideologiju kao društvenu tvorevinu koja je skup predstava kojima je ispunjen jezik sa kulturnim značenjem određenog društva, a često je povezana sa sistemima verovanja. „Kada su rodne karakteristike jezika u pitanju, one najčešće puno govore o tome na koji način funkcionišu $i$ kakve su prirode zajednica žena i muškaraca u datom društvu“ (Filipović, 2011: 414). Diskurzivna praksa određene društvene zajednice, kao što je u našem slučaju društvene zajednice u kojoj je jezik komunikacije poslovni engleski jezik, odražava kvalitet društvenih odnosa i moći unutar nje. „Ukoliko želimo da znamo kako ideologije zapravo izgledaju, kako funkcionišu i kako se stvaraju, menjaju i reprodukuju, trebalo bi da pažljivo pogledamo njihove diskurzivne manifestacije“ (van Dijk, 1998: 6).

Debra Tenen (1990) primećuje različite komunikativne obrasce ponašanja i govorenja između muškaraca i žena. S tim u vezi, ona navodi da su u poslovnoj komunikaciji žena više vidljive komunikativne strategije kao što su podrška i zajedništvo, dok se u interakciji muškaraca pre mogu primetiti znakovi dokazivanja, takmičarksi duh, i isticanje među članovima grupe. Ovo navodi na zaključak da „se hijerarhijska struktura muškoženskih grupa još više potencira, a žene postižu slabije rezultate na radnom mestu jednostavno jer su manje vidljive u komunikaciji i interakciji“" (Filipović, 2011: 412). Pored toga, analizom forme diskurzivne prakse muškaraca, može se primetiti da su oni institucionalizovani, te da žene koje se bave muškim zanimanjima često oponašaju takav govor, primera radi: žena policajac koristi formu verbalnog ponašanja kakav bi koristio njen kolega policajac (Tannen, 1995: 139).

U ovom radu korišćen je pristup kritičke sociolingvistike, koji, prema Ferklou (2001: 4) kao i svaka kritička teorija koja se primenju na istraživanje jezika i društvene interakcije, analizira ne samo lingivstičke segmente, nego i implicitne determinante u sistemu društvenih odnosa, kao i skrivene uticaje koje mogu imati u okviru sistema.

\section{METODA ISTRAŽIVANJA, KORPUS I UZORAK}

Za potrebe ovog rada pripremljen je upitnik pomoću kog su informacije dobijene direktno od ispitanika, koji su izabrani po jasnom kriterijumu. Kriterijum za selekciju ispitanika podrazumevao je da ispitanici i ispitanice poseduju znanje engleskog jezika na B nivou i koriste poslovni engleski jezik u svakodnevoj komunikaciji. Ukupan broj ispitanika je 56, starosti između 22 i 62 godine. Svi ispitanici i ispitanice poseduju visoku i višu školsku spremu. Takođe, vodilo se računa da njihov profesoinalni domen ne bude vezan za jezičko, odnosno lingvističko zvanje, jer se pretpostavlja da bi njihovo znanje uticalo na odgovore, ali i na samu analizu. Prema tome, velika pažnja je usmerena na to da grupa bude dovoljno reprezentativna na nivou šire društvene zajednice, jer se radi o rodno mešovitoj grupi, različitih visokih nivoa obrazovanja, koji poslovni engleski jezik koriste u različitim ambijentima. Suština samog istraživanja jeste da prikaže da li upotreba engleskog jezika u poslovnom kontekstu utiče na generisanje kulturnih modela i kreira rodnu ideologiju u društvu koja odražava nejednakost pri raspodeli društvene moći. Polazi se od pretpostavke da je tradicionalni patrijarhalni kulturni model u Srbiji još uvek veoma uticajan.

Upitnik, odnosno instrument istraživanja, bio je kombinovanog tipa što podrazumeva da je trebalo izabrati nešto od 
ponuđenih odgovora, ali i objasniti svoje mišljenje u vezi sa pojavom. Pitanja se odnose na morfološki rod imenica koja označavaju zanimanja žena i muškaraca u engleskom jeziku, ali i direktno ispituju njihove stavove o upotrebi i odnosu prema gramatičkom rodu, ali i o poziciji i ravnopravnoj vidljivosti žena, ne samo u jeziku, već i u društvu.

Svima je na početku anketiranja rečeno da ne postoje netačni odgovori. Ispitivanje je sprovedeno na teritoriji Republike Srbije u periodu februar - mart 2015. godine.

\subsection{REZULTATI ISTRAŽIVANJA}

Prvo pitanje je koncipirano tako da su ispitanicima/ispitanicama bile ponuđene tri kolone imenica iz engleskog jezika koje označavaju profesije i zanimanja: prva kolona bila je u muškom rodu, druga u ženskom i treća u neutralno markiranom rodu. Od ispitanika/ispitanica je zatraženo da odaberu one imenice kojima bi imenovali/le osobe ženskog pola. Odgovori ispitani$\mathrm{ka}$ /ispitanica na prvo pitanje u anketi se takođe mogu se podeliti u tri grupe. Prvu grupu odgovora čine 40 ispitanika/ispitanica koji su u odabiru morfoloških oblika u prvom pitanju ankete odabrali treću kolonu, rodno neutralni oblik imenica. Od ispitanika/ispitanica koji/e su odabrali/le treću kolonu zatraženo je da obrazlože svoj izbor. Mišljenja su ovako podeljena: 11 ispitanika/ispitanica smatra da su odabrali/le treću kolonu jer ona obuhvata oba pola, dok je preostalih 29 odgovorilo da taj oblik zvuči najpogodnije.

Drugu grupu odgovora čini 6 ispitanika/ispitanica koji su odabrali/le drugu kolonu, isključivo ženski rod, treću grupu čini 10 ispitanika/ispitanica koji su dali/le podeljene odgovore, odnosno u nekim poslovnim situacijama obratili/le bi se ženskoj osobi u ženskom rodu (spokeswoman, businesswoman, saleslady, stewardess), dok bi u drugim slučajevima odabrali/le rodno neutralnu imenicu (committee member, supervisor, sales agent).

Ukoliko bi se nametnula poslovna sitacija u kojoj se ispitanici/ispitanice moraju obratiti samo ženskoj osobi, 29 ispitanika/ ispitanica tvrdi da bi joj se obratila u ženskom rodu (chairwoman, saleslady, businesswoman, itd.), 19 ispitanika/ispitanica bi se obratilo u rodno neutralnom rodu (chairperson, salesagent, business executive), dok bi 8 ispitanika/ispitanica iskoristilo muški rod (chairman, salesman, businessman) uz objašnjenje da se u duhu engleskog jezika ti termini više koriste, dok se složenice ženskog roda i ne koriste. Ovo pitanje bi valjalo podrobnije ispitati u konkretnoj poslovnoj situaciji, a razlog tome može biti da je samo pitanje bilo sugestivno.

U odeljku gde je trebalo dati odgovor na pitanje da li smatraju da u poslovnoj komunikaciji treba insistirati na navođenju oba oblika imenica, ukoliko se radi o rodno mešovitoj grupi kojoj se obraćamo, 16 ispitanika/ispitanica je dalo odgovor da ne treba insistirati na tome budući da takvo obraćanje opterećuje jezički iskaz, preostalnih 40 ispitanika/ispitanica smatra da se rodno meštovitoj grupi obavezno treba obraćati u oba roda i da donekle opterećuje jezički iskaz, ali da je profesionalna korektnost najvažnija.

Odgovarajući na poslednje pitanje u anketi, ispitanici i ispitanice izjasnili/le su se da li upotreba rodno osetljivih termina u poslovnom engleskom jeziku doprinosi afirmaciji žena u profesionalnom svetu. Ovo pitanje je značajno jer na koherentan način daje eksplicitan uvid u vrednovanje ženske figure, ne samo u jeziku već u društvu. Prema sprovedenoj anketi 42 ispitanika/ ispitanica smatra da rodno osetljivi termini ne doprinose afirmaciji žena. Kao objašnjenje oni su ponudili da su „beskorisni izrazi koji komplikuju komunikaciju“, „suština ravnopravnosti nije u jeziku“, „upotreba ženskih imenica je deo mode u jezi- ku“, „afirmaciji žena doprinosi lična angažovanost i uspeh, a ne jezik“. Mnogi/e ispitanici i ispitanice su prokomentarisali/le da rodno osetljiv jezik u poslovnoj komunikaciji odmaže afirmaciji žena, jer se time stavlja akcenat na različitnost od muškaraca, a time implicira na nedovoljnu stručnost.

Preostalih 14 ispitanika/ ispitanica izražava vrlo jasan stav: „upotreba rodno osetljivih termina bi koristila afirmaciji žena i smanjila bi se diskriminacija, a povećala njihova vidljivost u poslovnom svetu; time bi postepeno došlo do izgranje sveti o tome da su žene u potpunosti ravnopravne sa muškarcima“, „rodno ravnopravan jezik je prvi korak ka ravnopravnom uključivanju žena u sve oblasti i profesija u društvu“, „obraćenjem ženama u ženskom rodu se izražava poštovanje i uvažavanje, a time se i podiže nivo poslovne komunikacije“, „jezik gradi stvarnost, a naše izražavanje jezikom je zapravo odraz prema društvu“, „trend u jeziku treba da ide u korak sa trendom u društvu: ustaljeno je da se u profesionalnom izražavanju afirmišu muškarci, a pošto su žene u sve većem broju prisutne u poslovnom svetu, $\mathrm{i}$ to na visokim pozicijama, treba postepeno menjati i praksu u jeziku“.

\section{ZAKLJUČCI}

Ovo istraživanje je pokazalo da najveći deo ispitanika/ispitanica koji/e svakodnevno korsite engleski jezik na svom radnom mestu preslikavaju jezičke obrasce iz svog jezika na strani. Iako je većina ispitanika/ispitanica u prvom pitanju odgovorilo da bi se ženskoj osobi obratili rodno neutralnim markiranim imenicama, odgovor da im tako zvuči najpogodnije govori u prilog tome da oni gramatički rod ne doživljavaju kao socijalnu kategoriju, već isključivo kao strukturu. Objašnjenja koja su data u poslednjem pitanju, takođe podupiru ovakav zaključak.

Patrijarhalni kulturni model preslikan je i u jezičkoj praksi na stranom jeziku, te se očigledno ipak favorizuju nazivi profesija u muškom rodu, ali u najboljem slučaju u neutrlno markiranom rodu. Prema mišljenju većine ispitanika ženski morfološki oblici imenica zvuče rogobatno, narušavaju principe jezičke ekonomije i ne treba insistirati na njima. Međutim, ovaj argument se ne smatra dovoljno validnim u tokovima savremene lingvistike ukoliko se pođe od činjenice da jezik kreira stvarnost. Jedno od važnih obeležja identiteta jedne osobe jeste aspekt profesije, pa shodno tome „upotreba muških oblika imenica koje označavaju nazive zanimanja i titula za žene jednostavno ukazuje na postojanje određenog društvenog konstrukta muškog identiteta" (Filipović, 2009: 137).

Pored toga, istraživanje pokazuje da je jezička ideologija svakog pojedinca čvrsto utemeljena u kulturi. To znači da svoje stavove i uverenja o kulturnim vrednostima unutar njihovog društva vezuju i za drugi, nematernji jezik, kao što je u ovom slučaju poslovni engleski jezik, iako komuniciraju sa ljudima koji pripadaju drugoj kulturi i drugačijem socijalnom miljeu, u kojima verovatno postoji sasvim drugačiji obrazac jezičkog ponašanja. Ovakav jezički kod može neretko dovesti do zabune u komunikaciji ukoliko se ne adaptiramo univerzalnom, neutralnom jezičkom kodeksu. Na primer, u nemačkom jeziku postoji morfološki oblik imenica, koje označavaju zanimanja, profesije i titule žena, koje su u upotrebi sasvim prihvaćene.

Interesantnim se čini i to da je ovo istraživanje takođe pokazalo da su mlađe osobe, uglavnom žene, bile svesnije potrebe da se kroz jezik obezbedi prisustvo žena u javnim sferama društvenog života. Ohrabrujuće je to da ukoliko se ovaj trend nastavi, a žene budu zauzimale pozicije koje su se u prethodnom periodu isključivo važile za muška zanimanja, mlađe generacije će osećati potrebu da u svoj mentalni leksikon utisnu značenje reči advokatica, psihološkinja, profesionalka, sudinica i slično, 
a time će se kreirati jedna nova društvena stvarnost gde će se jasno i prirodno pravi razlika između profesije muškaraca i žena.

\section{REFERENCE}

Biber, D., Conrad, S., \& Leech, G. N. \& Finegan, E. (1999). Longman Grammar of Spoken and Written English. Harlow: Longman.

Cameron, D. (2003). Gender and Language Ideologies, in:, Janet Holms \& Miriam Meyerhoff (eds.), The Handbook Of Language and Gender. Oxford: Blackwell Publishing, str. 447-467.

Čaušević, J., \& Zlotrg, S. (2011). Načini za prevladavanje diskriminacije u jeziku i obrazovanju, medijima i pravnim dokumentima. Sarajevo: Centar za interdisciplinarne i postdiplomske studije Univerziteta u Sarajevu.

Gamarnikow, E., et al. (1983). Gender, Class and Work', in Explorations in Sociology 18. London: Heinemann, str. 169179.

Gvozdanović, J. (2010). Diskurs o rodnoj ravnopravnosti u jeziku. Diskurs i diskursi, Zbornik u čast Svenki Savić (225- 229). Novi Sad: Filozofski fakultet.

Fairclough, N. (2001). Language and Power. Essex: Pearson Education Limited.
Filipović, J. (2009). Moć reči: Ogledi iz kritičke sociolingvistike. Beograd: Zadužbina Andrejević.

Filipović, J. (2011). Rod i jezik (Gender and Language), U: Ivana Milojević \& Slobodanka Marković (eds.), Uvod u rodne teorije (Indruduction in Gender Theories). Novi Sad: Centar za rodne studije \& Mediterran Publishing, str. 409- 423.

Frendo, E. (2007). How to teach Business English. Harlow: Longman.

Fuertes Olivares, P. A., Velasco Sacristán, M., \& Samaniego Fernández. (2003). Gender Sensitive in Specialized Communication: A preliminary corpus-based study of the LSP in Economics. Ibérica, 6, str. 65-87.

Hamer, J. (2006). The Practice of English language Teaching. London: Longman.

Tannen, D. (1990). Sex, lies and conversation: Why Is It So Hard for Men and Women to Talk to Each Other? The Washington Post, June 24, 1990.

Tannen, D. (1995). The Power of Talk. Harvard Business Review, September- October, str. 138- 148.

Thornbury, S. (2002) How to Teach Vocabulary? London: Longman.

Van Dijk, T. (1998). Ideology: A Multidisciplinary Approach. London: Sage Publications. 